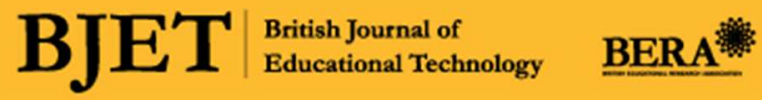

\section{Percolating spaces: creative ways of using digital technologies to connect young children's school and home lives}

\begin{tabular}{|r|l|}
\hline Journal: & British Journal of Educational Technology \\
\hline Manuscript ID & BJET-0010-Jan-2018-OMS.R3 \\
\hline Manuscript Type: & Original Manuscript \\
\hline Date Submitted by the Author: & n/a \\
\hline Complete List of Authors: & $\begin{array}{l}\text { Gillen, Julia; Lancaster University, Linguistics and English Language } \\
\text { Kucirkova, Natalia; University College London, Institute of Education }\end{array}$ \\
\hline Keywords: & $\begin{array}{l}\text { Case Study, Early years education, posthumanism, technologies, } \\
\text { classroom-ness }\end{array}$ \\
\hline \multicolumn{2}{|l}{} \\
\hline
\end{tabular}

SCHOLARONE ${ }^{\text {M }}$

Manuscripts 


\section{Structured practitioner notes}

What is already known about this topic:

- There are often reported gaps between what is known about children's digital technology use at home and at school;

- Some early years settings have diverse technologies but the use of these is not always subject to effective pedagogy;

- It can be challenging to make links between what happens in the moment in a classroom, processes of pedagogic design and assessment, and school policy.

What this paper adds

- Examples of design and of pedagogic practice that connect with children's home experiences with digital technologies;

- Suggestions of the importance, and benefits, of making links with young children's families with regard to the use of digital technologies, in a variety of modes;

- A way of conceptualising the production of space that makes links between actions in the moment, pedagogic design and assessment, and school policy;

Implications for practice and/or policy

- There are multiple opportunities for Early Years settings to connect to children's home uses of technology;

- More explicit planning for incorporating children's home experiences with technology into the classroom settings is needed for effective practice. 


\section{Percolating spaces: creative ways of using digital technologies to connect young} children's school and home lives

Address for correspondence:

Dr Julia Gillen, Dept of Linguistics and English Language, Lancaster University LA1 4YL. Email: j.gillen@lancaster.ac.uk

Phone: +44 (0)1524 510830

Fax: +44 (0)1524 493045

\section{Biographies}

Dr Julia Gillen is Reader in Digital Literacies and Director of the Lancaster Literacy Research Centre, Lancaster University. She researches the digital literacy practices of children and young people in and out of school. Her most recent book is "Digital Literacies" (Routledge, 2014).

Dr Natalia Kucirkova is Senior Research Fellow at the UCL Institute of Education. She researches innovative ways of supporting children's reading engagement with digital books and the role of personalisation in early years. She co-edits the Bloomsbury Academic Book Series 'Children's Reading and Writing on Screen' and chairs the UKLA Children's Digital Book Awards. 


\begin{abstract}
Contemporary research suggests there are many missed opportunities for home and school to work together to define and promote effective practices with digital technologies, especially in early years. This study outlines ways in which one Early Years classroom creatively promoted bidirectional connections between children's learning with technologies at home and in school. Nested in a posthumanist perspective on space and classroomness (Burnett, 2014), the study illuminates the complex spatial entanglement among home, school and technologies in the form of enhanced vignettes. As a space-based interpretive case study that emerged from a larger project, the data collection methods revolved around a set of two visits by each researcher, one year apart, plus analyses of school documentation and online interactions. We integrate diverse data sources to argue that innovative, multimodal practices of teaching, learning and assessment can be designed and implemented imaginatively, deploying a range of digital technologies to connect with children's and parents' home lives. Use of multimedia affordances of technologies, attention to children's physical and material interactions with resources and strategic school policy made it possible for influences to percolate between home and school, to the enhancement of children's learning in the moment.
\end{abstract}

\title{
Introduction
}

Background

In Europe, children are "daily in contact with a wide range of digital tools" (Chaudron, 2015, p.7). In the UK, there is a general pervasiveness of digital technologies in society, and it has been claimed since 2005 that young children are growing up in a "digital world" (Marsh et al., 2005). While inequalities continue in the diversity and quality of access by young children, an important issue for Early Years education (up to 8 years old, Year 2 in primary schools in England and Wales) is a frequent disjuncture between home and school practices with digital technologies involving young children.

Practitioners in pre-school settings have little awareness of young children's home use of digital technologies and indeed, their media-related lives in general (Aubrey \& Dahl, 2014; Plowman, McPake, \& Stephen, 2010). Some educators find it challenging to cope with the fast pace of technological change themselves (Kucirkova, 2017) and others are concerned that digital technologies may have adverse effects on children's learning (Wolfe \& Flewitt, 2010). This lack of awareness extends in the other direction too, as across Europe parents report knowing little about their children's digital activities in the nursery, kindergarten or at school (Livingstone, Mascheroni, Dreier, Chaudron, \& Lagae, 2015; Marsh et al., 2005; McPake, Plowman, \& Stephen, 2013). Yet, a recent review of these issues as researched between 2005 and 2015, concluded that: "Parents would welcome stronger and more collaborative relationships with early years settings, with information-sharing and exchange of good practice regarding the use of technologies in the home to promote and enhance

| learning and development." (Kumpulainen \& Gillen, 2017: 24). Later research has continued to strengthen findings that children's engagement with digital technologies is part of everyday life in the home (Palaiologou, 2016). Parents are convinced of benefits of appropriate use and want more integration with their learning in Early Years settings (Kumpulainen \& Gillen, forthcoming). 
In light of evidence that there are many missed opportunities for home and school to work together to promote effective practices with digital technologies, this paper aims to identify and discuss practices that make use of these opportunities to facilitate children's learning. Effectiveness in UK schools may be identified at local, national and international levels. Our definition of effectiveness is based on two factors: first, the external assessments of the school's performance and second, a theorized understanding of what we consider "excellence" and "best practice" in relation to the specific area of technology-mediated home-school connections.

This study was part of a large-scale research project conducted in England, Wales and Scotland in 2015-16 New Purposes, New Practices, New Pedagogies, (NP3) led by Peter Twining at the Open University. The project aimed to investigate the digital practices that pupils bring to their learning in school and the methods with which teachers' pedagogic practices made connections with these. The school had identified itself to the NP3 project as interested in effective practices in these areas, offering as evidence an external assessment of the school's success by the UK's Office for Standards in Education, Children's Services and Skills (Ofsted), especially as appertaining to the Early Years. In 2013, two years before our project began, Ofsted judged the school as good with outstanding features in leadership and management, behaviour and safety of pupils. Children in Early Years, the focus of this paper, had been regarded as making "outstanding progress". In 2015, all children made expected or better progress in government-set Key Stage 1 and Key Stage 2 standard assessment tests of Maths and English at ages 7 and 11-. If the effectiveness of home-school relations could be measured, then based on our subjective judgment of observing the school's practices during separate visits, the school would score highly. In this paper we explain why and how. We documented in detail the ways in which the teachers joined the use of technologies between school and home and how the children used technologies at home that connected to their use in the classroom. The theoretical framework which guided our data analysis springs from a New Literacies discourse (Burnett, Davies, Merchant, \& Rowsell, 2014) with Burnett's (2014) specific spatialized perspective. This theoretical orientation moves us towards an alignment with a currently fertile post-humanist territory growing in Early Childhood Literacy research (see, e.g., Kuby \& Gutshall Rucker, 2016; Kuby \& Rowsell, 2017b). We explore this framework in more detail next.

\section{Theoretical Framework}

New Literacies is a rich frame, which positions children's reading and writing as part of a complex "ensemble of social, cultural and economic connections" (Freebody, 2014: xi). New Literacies research that traces such connections, including when focussing on children's literacies and uses of technologies between homes and schools, is increasingly turning to spatial perspectives (Mills \& Comber, 2015). As other scholars working with space-based approaches, we understand space as relational, and therefore, as having intrinsic implications for our methods of data generation and analysis. Especially useful to us has been Burnett's (2014) spatial perspective on "classroom-ness". Burnett (ibid) looks beyond binaries such as home and school, online and offline, through being aware of multiple connections between these, as experienced in human practices. "By 'classroom-ness' I emphasise both the distinctiveness of classroom spaces and their hybridity and fluidity" writes Burnett (2014, p. 193) and, drawing on the work of Massey (2005), Burnett (2014) perceives the relationship between space and practice as not only interlinked, but also mutually constitutive. This definition is useful in acknowledging "the positive affordances of the school as a meeting place" and the crucial collective and collaborative dimension of learning facilitated by schools (Comber, 2016, p.155). Classroom-ness thus challenges established research and 
practice conceptualisations of learning within the classroom. If we don't focus on connections between school and home, we "miss opportunities to investigate learning when it flows..... across time and settings" (Barron, 2006, p. 193).

Massey (2005) proposed three characteristics of how we might understand space: first, space is constituted through interrelations and interactions; second, space is a cross-section of distinct trajectories that give rise to "coexisting heterogeneity" (p.9), and third, space is never finished and always in flux of development. Massey thus takes an anti-essentialist approach to space and recognises the essential heterogeneity and fluidity of sense-making in any particular environment: "If no space/place is a coherent seamless authenticity then one issue which is raised is the question of its internal negotiation" (Massey, 2005, p.10).

Burnett's notion of classroom-ness and Massey's conceptualisation of space informed our theoretical disposition as well as methodology. Awareness of constant change and recognition of complexity move theory and method together into a posthumanist arena. Possibly, the "posthumanist" label is a misnomer in suggesting a temporal state of being "after" the "human", which is doubly unhelpful. However, posthumanist approaches in early childhood research are taking us usefully beyond the limited social constructivist model of interactions of "human" plus "tool" towards an ultimately more productive conceptualisation: of entanglements of environments/technologies/human/nonhumans (Hultman \& Lenz Taguchi, 2010). As technologies become more diverse; our ways of interacting - and intraacting (i.e. through mutual adaptation and inter-penetrations in various ways) also develop and diversify. In a posthumanist approach children's interactions are viewed as embodied and entangled with the material entities around them (Hackett \& Somerville, 2017). Thus our understanding of literacies moves from a centrally linguistic focus to a "material turn" involving more complex understandings of agency as distributed among human and nonhuman entities in practices (Kuby \& Rowsell, 2017a). The posthumanist approach to digital technologies thus appears a rich paradigm for studying young children's use of technologies in early years settings (e.g. (Kuby \& Rowsell, 2017b). It does not remove teachers' pedagogic practices from consideration but rather invites a rethinking of the researcher's starting place, requiring new ways of thinking and writing "with theories and matter in the world" (Kuby \& Rowsell, 2017a, p. 287).

\section{Aims and objectives}

Cognisant of the complex entanglements involved and the need to increase the empirical understanding of home-school connections, our aim was to explore what we perceived as opportunities with digital technologies that were presented in the setting and that appeared to us to creatively promote bidirectional influences between children's learning in school and at home. This aim was pursued by investigating three research questions:

RQ1 What interrelations among children, adults, digital technologies and other aspects of the environment enable connections to be made between home and school?

RQ2 How do the individual trajectories of teacher, child and parent co-exist in ways that support connections between home and school?

RQ3 Which school policies can be observed in practice, that enhance the possibilities for percolating spaces between home and school, with particular respect to learning with and through digital technologies? 
These research questions can be perceived as ways of instantiating Massey's (2005) three characteristics of space. The first concerns interactions and interrelations; the second focuses on the distinct individual trajectories and the third on the continual, non-finalisable construction of space. They were iteratively constructed as we sought to "think through" (Boldt \& Leander, 2017, p. 411), the activities we were observing within their and our own entanglements in the world.

\section{Method \\ Data collection}

In the NP3 project, the entire research team worked to identify effective practice through a mixture of methods in diverse schools, including video and audio observations, interviews, questionnaires, focus groups and study of physical and virtual artefacts in the school. This paper concerns our work in one school.

In this study, data generation began with the researchers studying the school's externallyfacing digital communications, such as the school's website, including blogs and Twitter feeds, one month before the first visit. Then the first author spent two days in the school, one week apart, to allow for the digital log exercise and compiling of teacher questionnaires with accompanying evidence generated in the interim. Our second set of visits undertaken by the second author occurred a year later and followed the same pattern. We worked with the Head Teacher, Ms Aspinall, the Deputy Head Teacher/ICT coordinator and seven teachers who provided documentation and artefacts regarding lesson planning, reflections and examples of children's work. Other adults were sometimes present but not involved other than in observations and informal discussions. During each first visit to the school, a "digital log" exercise was co-designed with pupils and their parents or carers, to better understand home practices with technologies. The digital log recorded the child's interactions with digital technologies out of school, on both a week night and a weekend day. The recordings were made in whatever mode suited the child and family: pen and paper; photos; vlogs etc. This data was discussed by participants with the researchers in two meetings, before and after the data generation. (see Twining et al., 2017 for a fuller account of the project's methods).

\section{Methodology}

Given the understanding of space as always under construction in interactions by unique individual meaning-making trajectories, we have to recognise our own responsibilities in the data collection process. In complex evolving spaces, researchers cannot simply "collect" data, as if data were an inert material somehow separated from human understandings, but rather acknowledge their own role in "generating data", as urged by Thomson and Hall (2017).

We present our data first in the form of "examples of classroom-ness" (Burnett, 2014, p. 198) drawing on sources of evidence relating to our observations. In previous work we have described and conceptualised these brief accounts, often accompanied by an image, as a "vignette", recognising that this term has been used in multiple ways (see Gillen \& Cameron, 2010). In this paper, we are responding to the particular emphasis on space as relationally constructed, by heterogeneous voices, in presenting what we will call enhanced vignettes. We draw on the images, fieldnotes, audio and occasionally video data that we collected during observations. The fieldnotes were improved shortly after the observations into more coherent prose. We then select from our other sources of data such as transcripts of focus groups or interviews, photographs or notes taken at another time and elsewhere in the school to further inflect the present tense accounts garnered from fieldnotes and observational data. Thus, the additional material is used to provide nuanced layers to the present tense accounts. 
We have selected and then crafted our enhanced vignettes so that they respond to the three research questions, while illustrating the complex mix of technologies present in this school's practices. We applied three criteria to select exemplar enhanced vignettes: 1, the examples needed to effectively capture the quality of classroomness in the moment; 2 , connections needed to be available in our data that we could use to relate to Massey's (2005) three characteristics of space; and 3) holistically, the enhanced vignette needed to contribute to our overall aim. Our methodological approach and the particular way in which we analysed and presented our data, are aligned with space-based interpretive case study methodologies (Comber, 2016; Dyson \& Genishi, 2005; Mills \& Comber, 2015). We recognise, from our shared background in Literacy Studies with its particular valuing of ethnographic perspectives and attention to multimodality and embodiment, that, all such interpretive work stems strongly from the researchers' positionality and subjectivities (Dyson \& Genishi, 2005; Hackett, 2017). A key theme in postmodern theory is the need to challenge traditional notions of truth and evidence (see Taylor, 2016), thus acknowledging researchers not as those who report "truth" but rather as those who critically reflect on the human-material entanglements involved in producing reality. We analysed the data through discussion between us, the two authors, which meant that while choosing and analysing our examples, we extended our own understandings of what we observed.

\section{Results}

Enhanced vignette A

We begin with an account of approximately ten minutes in the Early Years classroom, involving five focus children, aged between 3 years and 4 months and 5 years 1 month. The youngest children had only been in the nursery for seven weeks.

\section{Fieldnotes extract 1:}

"The activity begins by focussing on different types of voices. Flashcards represent the different voices. These are tackled in pairs, after a child has selected two. For example there is a 'croaky voice' and a 'laughing voice.' The children then listen to an animation on the tablet, amplified through two loudspeakers. They cannot see the screen until after they have guessed which it was. So, after each child has guessed, for example by showing their hands or shaking head (being prompted to talk but not always doing so) whether the voice is of a croaky or laughing voice, they are then shown the animation on the tablet, e.g. a frog croaking the first line of Twinkle Twinkle Little Star... Miss Hudson then develops the activity into encouraging the focus children to practice different voices. On her tablet she displays images of each of the children in this group. At this point she selects one of them and then asks the child to say/sing the first line of Twinkle in a certain kind of voice, e.g. 'a deep voice."”

In this session, the teacher skilfully drew on the affordances of the technology to stretch the children's capacities. The focus on children's voices and the audio possibilities of tablets activated and mediated children's enjoyment and engagement in the session. The teacher's use of children's pictures as visual clues on the tablet reflected her creative and competent navigation of the technologies, which added to the interrelationship between children's multimodal engagement in the session and the technology affordances.

\section{Fieldnotes extract 2:}

"The two phases of the activity were quite demanding of all children... Miss Hudson made various connections with other activities e.g. to a previous activity in making animal sounds, 
and also forwards, promising to revisit the activity tomorrow. She used it to explore concepts of opposites, such as fast and slow, for example. This appeared to be appropriately pitched to the children's level of understanding and capabilities. For example, speaking at a pace different from one's normal pace was very difficult if not impossible, but on the other hand, aspects of understanding 'fast' were demonstrated multimodally through embodiment, e.g. children imitating, and modifying, Miss Hudson's demonstration of fast movement with her arms to illustrate "fast."

Immediately after the session, the researcher interviewed Miss Hudson. The NP3 project had provided some funding for teacher cover so that this interview could take place immediately after the observed session. Miss Hudson began her account by summarising: "That was phonics". She explained this a subsequent step to an initial activity of making animal noises that she had blogged about. Later we found the blog referred to a zookeeper story:

Blog extract 1:

"This morning Nursery were contacted by a very sad zookeeper.

All of the animals in her zoo had lost their voice. Since we were such good experts on animals the zookeeper asked the children to teach the animals how to make their noises again. We thought about each animals noise and whether they made loud/quiet, long/short and soft/scary sounds.

Look below at our videos of the animals making their noises.

A noisy pig's grunt

A wolf's scary howl..."

[and 8 other examples, each animal sound linking to a video]

The teacher had explained why she writes such a detailed blog about activities like this. "The big thing is when you open the door at home time they open the door and go 'Mum ...... we did this and we did that', and they just instantly recall everything that they they've done, so that's brilliant when that happens, This is why the blog is so good as well because sometimes they go out, when they.re quite young it's a garbled message, and they get a few words right but all in the wrong order, and Mum's like 'What have you done?' So that's why on the blog then I explain it all, and often in the comments, parents will comment back, oh, I think the bear hunt one, Kayleigh would be on her own bear hunt at home, so she'd tried to re-do it again, so you get a lot of re-learning that way as well. "

Miss Hudson explained that this animal sounds activity had been expanded into a multimedia approach to beginning phonics that featured diverse entanglements of technologies and activities. For example an area outside the school had been set up as various animal habitats. Each included digital talking tins that displayed the image of an animal, its name, and when pressed, made an associated sound. We studied an assessment record of focus pupil Billy based on an observation of him there. Photographs and a narrative describe his use of the talking tin in the setting, and his connections between different symbols and sounds associated with donkeys, including his own imitation of a donkey's bray.

The following page in the record details an occasion when Miss Hudson had scheduled an individual observation of Billy in the classroom. Billy asked to use a desktop computer. The teacher responded to his request to open a particular app, Espresso, which Billy wanted to use to design a pirate as he had already learnt to do this at home. Miss Hudson asked him about his home activities and included in the written observations Billy's accounts of his previous 
knowledge gained with parents, for example as how to open and shut the DVD drawer. He demonstrated skills with the mouse and various manipulations with effects on screen. She was careful not to jump in too quickly, either to assume competence or leap in for him. This was evident through her careful descriptions, for example: "When I clicked 'Save' a name box popped up on screen. I didn't say a word but Billy said [all three words of his full name] beginning with a ' $\mathrm{B}$ '." Billy asked to print out his digital artefact and take it home. This was granted, and while it entailed a walk through the school to the printer, this was valued and the account included Billy's discussion of the "animal habitats" when glimpsing this area through a window.

The observations produced by the teacher, contained at the end of the page colour coded symbols, which were part of the assessment tool used in the EY classroom, Startracker, through which the child's achievements are logged, questions raised and new possibilities imagined. It is important to mention that these practices of "pedagogical documentation" are used in a process of collective discussion and interpretation by the adults around the child, rather than as a box-ticking exercise (Dahlberg, Moss, \& Pence, 2013).

The rich trajectories between the digital resources and children's home-school lives were visible to us in the ways the children and teachers interacted together and moved around the classroom as well as the artefacts they produced. For the latter, the blog written by the teacher with the parent's audience in mind or the document produced by the child in the classroom to take home, illustrate the visible traces of home-school trajectories mediated by the technologies.

This vignette showed several moments in which binaries of home and school were overcome through entanglements. For example, at one moment the processes of operating a PC at home were called upon and re-enacted in the classroom setting. Blog posts involved connections between the school's outside space, conventional representations of animal noises as learnt by children across settings, and the subject matter of phonics so prominent in national policy documents. These interpenetrations constituted space through interactions. The trajectory of phonetics policies translated into classroom-based aims were different from the child's imaginative trajectory driven by the "zookeeper" fiction and both are likely to have been different from a parent's understanding of the activities, yet in this enhanced vignette each met in dialogic and "unfinalizable" ways.

\section{Enhanced vignette $B$}

In her fieldnotes, the second researcher noticed the diversity of technologies present at "free play time". The activities made available in this slot have been carefully planned and designed, as captured in this fieldnotes' extract.

Fieldnotes extract 3:

"A group of three young boys hold digital metal detectors, one each in their hands, and eagerly search for metallic objects in the classroom. They place the detectors on the furniture, toys, walls and clothes of their friends. The teacher takes part in the activity by encouraging one of the boys to place the metal detector on her earring. The detector makes a loud 'beep' sound and both Miss Hudson and the boy burst into laughter. The teacher then directs the boys to the sand tray in which she had placed small magnets attached to laminated numbers and letters. The boys enjoy the activity and shout over each other as they retrieve individual magnets 'An eight, I got an eight!' 'I found Ssss!'” 
There are three interesting features we would point to here. First, is the presence of the metal detectors, one element of the noticeable range of technologies in the EY classroom. These included an interactive whiteboard at one end of the classroom, another smaller stationary interactive screen at the other end, coding Bee Bots (small programmable floor robots), stopwatches, visualizers and digital cameras and a music system with loudspeakers at children's disposal. In addition, like the older children in the school, the EY children had the possibility to use a bank of notebooks and iPads on a regular basis. Our investigation of the technologies used in homes by families and teachers revealed that while some of the technologies, such as large screens and music systems, were familiar in many homes, others including digital metal detectors were wholly novel to this setting and experienced by the children as exciting and stimulating. Interviews with the teachers and senior leadership team revealed that new devices were purchased through the school's joint ICT budget. The school policy was that every classroom would submit proposals for new technology and a joint decision was made about which device was purchased. The staff were aware of the many technologies available to the children and were discerning about how the ICT budget was spent.

The second interesting feature about this activity was the way in which the teacher had planned this voluntary activity, so that it, as all other choices, contained some inherent curricular links: in this case to the identification of letters and numbers. This was a manifestation of the Ms Aspinall's determination "...to weave ICT into all aspects of school life," including a strong emphasis on observation and recording children's achievements in detail and planning.

Third, lies the recognition by parents that technologies can support school-related skills. In a digital log discussion, a parent with an older child at the school and a three year old, told us how she supports her younger child's developing knowledge of letters, shapes and material properties: "Even down to the Sky TV, she knows how to rewind and fast-forward and go in the planner and find a program that she likes.....Yeah, she looks for ' $\mathrm{D}$ ' for Dora, she stands close to the screen and goes 'There's a ' $d$ '" and then she says, 'Is this Dora Mummy?' and I say, 'Yes this is Dora.' And then she says, 'I'll press play, it's the triangle,' so she knows it's the triangle." This displays an awareness of the possibility to enrich mundane everyday experiences with technologies as pedagogic opportunities that has carried through to parents.

The sandpit with buried metal letters and numbers, accessible by digital metal detectors, thus offered an opportunity for the pursuit of traditional and foundational early learning goals, the identification of letters and numbers. Yet in this form the activity, entwining the digital and physical, was particularly engaging for the children. In our observation and the reported observation by the parent, we perceived the construction of space in interactions, and the very particular, indeed unique interrelationship or entanglement between environment, technology and child in each case. The diverse trajectories of the people involved were discernible and some of these connected to policies and practices aimed at effective learning in the classroom.

\section{Enhanced vignette $C$}

Fieldnotes extract 4 :

"At the end of the morning session, when the nursery children have their coats on, they move to the front of a portable touchscreen on a very low table. Another adult helps manage the space; children are called to move forwards and backwards as turn-taking is managed. Assistance is needed occasionally as bodies, bags and coats have to shift. 
"The activity concerns the identification of shapes and colouring them in with a specified colour. This appears to me to be (appropriately) stretching in that each child has to think about shape and colour and make the right moves on screen. Shapes are not necessarily isolated, for example a square house contains shapes representing windows within it.

"Abigail, aged 3 years and 9 months, is asked to look for a circle and colour it in yellow. This appears not to be easy for her as she uses pink. She then shuffles back as others take their turns. Miss Hudson again asks Abigail to take a turn. Abigail is about to paint a sun when the teacher says, 'Can you paint sunshine yellow?' Abigail answers, 'I don't like yellow' and paints the sun purple. She then points outside and says 'It's cloud,' establishing a link to the world outside on a very cloudy day. Miss Hudson is plainly convinced Abigail can identify yellow and has made an alternative choice, with justifications, and so moves the talk onto another topic."

Abigail is perhaps especially attuned to multimodality; her parents are profoundly deaf. Before she entered the school, the teacher had visited her home as she did with all the families. Miss Hudson knew some British Sign Language and made the most of this in communicating with the parents. Abigail had been encouraged to show some of the activities she most enjoyed; these included dancing and playing with her play kitchen. Photos taken on that day at home formed the first page of her school record book, another page concerned photographs with a description of her first school visit and verbatim quotations of five sentences under a subheading, "What I had to say". The record book contained many mentions of school home connections, for example recording when she had made and decorated a biscuit in school to take home. Abigail's bilingualism is evidently flourishing.

When asked about her priorities for a good lesson, Ms Aspinall had stressed, first, the warmth of the relationship between the adult and child, then the planned lesson structure and thirdly, the dialogic aspect to teaching, checking for feedback and ascertaining that learning is taking place. "If something isn't working you have to have the courage to abandon it, and change, and you should be able to see progress within the lesson." This interview quote reflects the school's ethos to use technologies if they are helpful but not at the expense of good pedagogy. Attention to checking for evidence of learning in the moment are prioritised.

In interviews, the school policies on keeping in close touch with all parents and carers were evident and take place across multiple modes. For instance, after explaining her time in the playground before school the Head teacher said, "We text, we write, we use the website." She then explained how the Early Years parents had been invited in before the end of school to "a blog lesson" and showed how to contribute on the interactive whiteboard. During the summer holidays children and parents put up photos and information about what they had done. Connections to school life were manifest even here, as some families came in to tend to the school's livestock and garden produce.

Overall, this enhanced vignette illustrates the desire to transcend unhelpful binaries in attention to classroomness (Burnett, 2014) presents instantiations of Massey's (2005) three characteristics of space.

\section{Discussion}

We adopted Massey's (2005) threefold characterisation of the production of space in our enhanced vignettes, aiming to elucidate the ways in which we understand "space as an open 
ongoing production" (Massey, 2005, p. 55). The "dynamic multiplicity" (ibid) of space is imbued with different trajectories, thus diverse participants are playing roles in intersecting scales of temporality. This approach to evidence and documentation of children's interaction with technologies is intentionally different from "utilitarian" research approaches that often perpetuate adult-child hierarchies and power relationships (see Elwick \& Sumsion, 2013).

First, we have communicated three occasions in which space is produced through interactions. These have involved children, adults and diverse technologies. The focus on the small scale and momentary interactions, is warranted as indeed, "change requires interaction" (Massey, 2005, p. 55). Glimpses of "classroomness" are necessarily mediated by our own lenses as researchers, yet can nonetheless resonate as examples of entanglements of technologies, and people, as together new, emergent meanings are produced, often ephemerally. As (Taylor, 2016, p. 18) observes, "posthumanist research is an enactment of knowing-in-being that emerges in the event of doing research itself."

In response to our first research question, we have seen how the children's home lives, including their interactions with technologies, inflect their moment-by-moment activities in the classroom and how knowledge and understanding of these by the teacher makes these productive. With touchscreens, the devices used at home and in school often look the same, but may be used for different purposes. How exactly children's perceptions of technologies relate to their engagement with the devices needs to be further explored in future research. In this study, multiple modes, such as sounds in enhanced vignette A, touch in enhanced vignette $\mathrm{B}$, and colour in enhanced vignette $\mathrm{C}$, contributed to entanglements in the moment and, we have argued, connections between home and school.

With regard to our second research question, we have seen how space is produced through the coexistence of multiple trajectories. Especially present in the classroom are the distinct trajectories of the children and teachers. We could observe how "children intra-act with materials" (Kuby \& Gutshall Rucker, 2016, p.62), that is how their whole bodies are engaged in activities in which they demonstrate positive affect, whether it was an engagement with the PC or the children and their coats shuffling forwards and backwards to engage with the touchscreen on the floor. Burnett's notion of classroom-ness, which challenges the homeschool binary, became particularly salient in adults' facilitation of technology use and children's appropriation of the adults' mediation. The teacher who designed activities and put them into place had pedagogic plans that were to some extent personalised for each child as mapped by the Startracker system. Behind such design lies knowledge and understanding about those children's home-based activities and how links can be fostered with them. Thus, although less obviously visible in the classroom, the project methodology permitted us to trace distinct connections from home to school enabling knowledge flows among children, parents and teachers, mediated through face-to-face interactions, Twitter dialogues, blog posts and comments.

In response to the third research question, our multifaceted approach to classroomness in enhanced vignettes enabled us to better understand how meanings percolated through the momentary interactions in which change, and learning, occurred. Our discussions with teachers such as Miss Hudson, Ms Aspinall and others revealed the multiple ways in which school policies were translated into curriculum design, lesson planning and the qualities of pedagogic interaction in the moment, exemplifying the recommendation by Marsh, (2016: 192) that "practitioners should make any assumptions about children's prior digital literacy competences without close observation and assessment, as that may lead to an exacerbation

Formatted: Not Highlight
Formatted: Not Highlight
Formatted: Not Highlight

Formatted: Not Highlight

Formatted: Not Highlight

Formatted: Not Highlight 
of difference and a widening of digital divides." This is a highly practical exemplar of Kuby and Gutshall Rucker's (2016, p.58) notion that space is produced as always open and "curriculum unfolds in the moment."

\section{Conclusion}

This paper is one element of a substantial research study and takes into purview data generated at just one site. Undoubtedly further analyses could achieve more; for example both the teachers' questionnaires and the digital log exercises would repay more explicit attention.

Theoretically and methodologically, we have created and demonstrated an innovative take on posthumanism to contribute to the field of New Literacies. We drew on Burnett's (2014) binary-dissolving notion of classroomness combined with Massey's (2005) insights into space as socially produced. We realised our research questions could be aligned with Massey's (2005) characterisation of space to investigate effective practices with digital technologies in the Early Years classroom, making connections with homes. This has been a useful approach to examine complexities of meaning-making, through the generation of enhanced vignettes.

Finally, our study yielded insights into counteracting the often negative rhetoric about the use of technologies in Early Years. In a recent pan-European review of current Early Years practices concerning technologies in classrooms, Marsh, Kontovourki, Tafa, \& Saloma (2017) point out that many schools adopt a "protective" approach and create technology-free zones to oppose children's frequent technology use at home. Our findings show that connections between children's home and school technology lives can be consciously mapped to promote productive spaces for children's continuous and rich experiences.

\section{Acknowledgement}

The research took place as part of the New Purposes New Practices New Pedagogies NP3 project led by Peter Twining at the Open University, funded by the Society for Educational Studies. A full list of team members appears at the project website: http://edfutures.net/NP3 


\section{References}

Aubrey, C., \& Dahl, S. (2014). The confidence and competence in information and communication technologies of practitioners, parents and young children in the Early Years Foundation Stage. Early Years, 34(1), 94-108.

Barad, K. (2007). Meeting the universe halfway: quantum physics and the entanglement of matter and meaning. Durham, NC: Duke University Press.

Barron, B. (2006). Interest and self-sustained learning as catalysts of development: A learning ecology perspective. Human Development, 49(4), 193-224.

Boldt, G. M., \& Leander, K. M. (2017). Becoming through "the break": a post-human account of a child's play. Journal of Early Childhood Literacy, 17(3), 409-425.

Burnett, C. (2014). Investigating pupils' interactions around digital texts: a spatial perspective on the "classroom-ness" of digital literacy practices in schools. Educational Review, 66(2), 192-209. Burnett, C., Davies, J., Merchant, G., \& Rowsell, J. (Eds.). (2014). New literacies around the globe: policy and pedagogy. New York.

Chaudron, S. (2015). Young children (0-8) and digital technology: a qualitative exploratory study across seven countries. Luxembourg. Retrieved from https://ec.europa.eu/jrc

Comber, B. (2016). Literacy, place, and pedagogies of possibility. New York: Routledge.

Dahlberg, G., Moss, P., \& Pence, A. (2013). Beyond quality in early childhood education and care: languages of evaluation (3rd ed.). London: Routledge.

Dyson, A. H., \& Genishi, C. (2005). On the case: approaches to language and literacy research. New York: Teachers College Press/NCRLL.

Elwick, S., \& Sumsion, J. (2013). Moving beyond utilitarian perspectives of infant participation in participatory research: film-mediated research encounters. International Journal of Early Years Education, 21(4), 336-347.

Freebody, P. (2014). Foreward: Literacy and a new global citizenry? In C. Burnett, J. Davies, G. Merchant, \& J. Rowsell (Eds.), New literacies around the globe: policy and pedagogy (pp. xi-xviii). New York: Routledge.

Gillen, J., \& Cameron, C. A. (Eds.). (2010). International perspectives on early childhood research: A Day in the Life. Basingstoke, UK: Palgrave Macmillan.

Hackett, A. (2017). Multimodality and sensory ethnographies. In J. Rowsell \& K. Pahl (Eds.), The Routledge handbook of literacy studies (pp. 295-307). London and New York: Routledge.

Hackett, A., \& Somerville, M. (2017). Posthuman literacies: young children moving in time, place and more-than-human worlds. Journal of Early Childhood Literacy, 17(3), 374391.

Hultman, K., \& Lenz Taguchi, H. (2010). Challenging anthropocentric analysis of visual data: a relational materialist methodological approach to educational research. 
International Journal of Qualitative Studies in Education, 23(5), 525-542.

Kuby, C. R., \& Gutshall Rucker, T. (2016). Go be a writer! expanding the curricular boundaries of literacy learning with children. New York: Teachers College Press.

Kuby, C. R., \& Rowsell, J. (2017a). Early literacy and the posthuman: pedagogies and methodologies. Journal of Early Childhood Literacy, 17(3), 285-296.

Kuby, C. R., \& Rowsell, J. (Eds.). (2017b). Early literacy and the posthuman: pedagogies and methodologies. Special issue of the Journal of Early Childhood Literacy 17 (3).

Kucirkova, N. (2017). How Can Digital Personal(ized) Books Enrich the Language Arts Curriculum? The Reading Teacher, 71(3), 275-284.

Kumpulainen, K., \& Gillen, J. (forthcoming). Young children's digital literacy practices in homes: past, present and future research directions. In R. Flewitt, O. Erstad, Kuemmerling-Meibauer.Bettina, \& I. Pereira (Eds.), The Routledge Handbook of Digital Literacies in Early Childhood. Abingdon, UK: Routledge.

Kumpulainen, K., \& Gillen, J. (2017). A review of literature on young children's digital literacy practices in the home. Retrieved from www.digilitey.eu

Livingstone, S., Mascheroni, G., Dreier, M., Chaudron, S., \& Lagae, K. (2015). How parents of young children manage digital devices at home: the role of income, education and parental style. London. Retrieved from http://www.lse.ac.uk/media@1se/research/EUKidsOnline/EUKidsIV/PDF/Parentalmedia tion.pdf

Marsh, J. (2016). The digital literacy skills and competences of children of pre-school age. Media Education: Studi, Ricerche, Buone Pratiche, 7(2), 178-195.

Marsh, J., Brooks, G., Hughes, J., Ritchie, L., Roberts, S., \& Wright, K. (2005). Digital beginnings: Young children's use of popular culture, media and new technologies. Sheffield. Retrieved from http://www.digitalbeginnings.shef.ac.uk/DigitalBeginningsReport.pdf

Marsh, J., Kontovourki, S., Tafa, E., \& Saloma, S. (2017). Developing Digital Literacy in Early Years Settings: Professional Development Needs for Practitioners. A White Paper. Retrieved from digilitey.eu

Massey, D. (2005). For Space. London: SAGE Publications.

McPake, J., Plowman, L., \& Stephen, C. (2013). Pre-school children creating and communicating with digital technologies in the home. British Journal of Educational Technology, 44(3), 421-431.

Mills, K. A., \& Comber, B. (2015). Socio-spatial approaches to literacy studies: rethinking the social constitution and politics of space. In J. Rowsell \& K. Pahl (Eds.), The Routledge handbook of literacy studies (pp. 91-103). Abingdon, UK.

Palaiologou, I. (2016). Teachers' dispositions towards the role of digital devices in playbased pedagogy in early childhood education. Early Years, 36(3), 305-321.

Plowman, L., McPake, J., \& Stephen, C. (2010). The Technologisation of Childhood? Young Children and Technology in the Home. Children \& Society, 24(1), 63-74.

Taylor, C. A. (2016). Edu-crafting a cacophonous ecology: posthumanist research practices for education. In C. A. Taylor \& C. Hughes (Eds.), Posthuman research practices in education (pp. 5-24). Basingstoke, UK: Palgrave Macmillan.

Thomson, P., \& Hall, C. (2017). Place-based methods for researching schools. London: Bloomsbury Academic.

Twining, P., Browne, N., Murphy, P., Hempel-Jorgensen, A., Harrison, S., \& Parmar, N. (2017). NP3 New Purposes New Practices New Pedagogy Meta-Analysis Report. London. Retrieved from http://edfutures.net/images/e/e7/NP3_Meta-analysis_report.pdf

Wolfe, S., \& Flewitt, R. (2010). New technologies, new multimodal literacy practices and young children's metacognitive development. Cambridge Journal of Education, 40(4), 
387-399. 